\title{
Persistent left superior vena cava mistaken for nodal metastasis: a case report
}

\author{
Vasilios Tzilas*, Antonios Bastas, Aspasia Koti, Dimitra Papandrinopoulou and Georgios Tsoukalas
}

\begin{abstract}
Introduction: Evaluation of the mediastinum is crucial for patients with lung cancer. Mediastinal lymph node metastases play a dramatic role in the process of staging. Physicians should be aware of the potential pitfalls regarding mediastinal evaluation. This case report provides an example.

Case presentation: We report the case of a 57-year-old Caucasian man who presented with a four-month history of non-productive cough. He was diagnosed with non-small cell lung cancer. Initially, it was thought to be inoperable due to the presence of a para-aortic lymph node. A more careful examination of the mediastinum revealed that the "lymph node" was in fact a persistent left superior vena cava.

Conclusions: This study highlights the difficulties in mediastinal staging, especially when intravenous contrast is not used. The recognition of this vascular malformation dramatically changed the therapeutic decisions, giving our patient the opportunity of surgical resection. To the best of our knowledge, such correlation has not been described in English literature.
\end{abstract}

\section{Introduction}

Persistent left superior vena cava (PLSVC) is a rare vascular abnormality. It is, however, the most frequent abnormality of the mediastinal veins. The prevalence is estimated to be $0.3 \%$ in the general population. It is higher (up to $4.5 \%$ ) in cases of congenital heart disease $[1,2]$.

The key point for diagnosis is the identification of the course of the aberrant vessel. It begins from the left branchiocephalic vein (at the junction of the left subclavian and internal jugular veins) which is usually hypoplastic (65\%). In 10 to $18 \%$ of cases there is absence of the (right) superior vena cava. PLSVC passes lateral to the aortic arch, anterior to the left hilum, crosses posterior to the posterior wall of the left atrium. It drains to the right atrium $(90 \%)$ or, rarely, to the left atrium (10\%). The latter case is frequently associated with atrial septal defects (ASD) and is a cause of shunt, usually of no clinical significance [3-5].

\footnotetext{
*Correspondence: tzilasvasilios@yahoo.gr

1 th Respiratory Medicine Department, Athens Chest Disease Hospital Sotiria, Greece

Full list of author information is available at the end of the article
}

\section{Case presentation}

A 57-year-old Caucasian man presented to our clinic with a four-month history of chronic cough. He was a heavy smoker with a history of 80 packs per year. A chest X-ray revealed a nodule in the left upper lobe (LUL). A computed tomography (CT) scan of the thorax confirmed the presence of a round nodule in the LUL with smooth margins (Figure 1). It also revealed a "nodule" in the mediastinum, which was initially thought to represent $\mathrm{N}_{2}$ mediastinal lymph node (station 6-para-aortic, Figures 2, $3,4,5,6)$.

During bronchoscopy there were no abnormal findings. Cytological evaluation of the obtained washings was negative for the presence of neoplastic cells. Finally, diagnosis was established with transthoracic fine needle biopsy which showed non small cell lung cancer (NSCLC). Initially, our patient was staged as IIIA, because of N2 disease. Thus, he was considered as a candidate for chemotherapy. However, a more detailed examination of the mediastinum revealed that the "nodule" was present in continuous levels. Therefore, it had an elongated shape. An elongated shape is characteristic of a tubular structure (e.g. a vessel) and is not seen in lymph nodes. Also, an anatomic correlation with the left branchiocephalic vein was identified. Finally, it is of great interest 


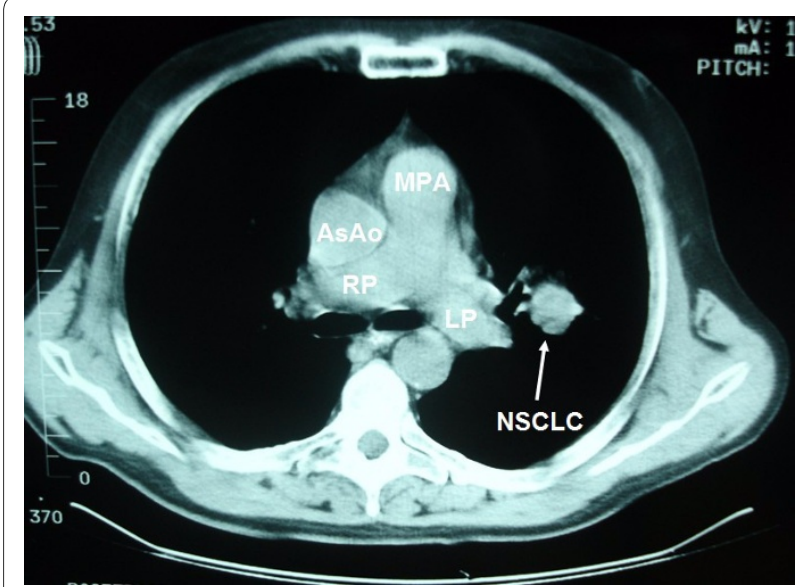

Figure 1 Non small cell lung cancer in the left parahilar area.

the absence of the azygous arch. There is, however, a prominent left superior intercostal vein (LSIV) which serves the same function creating a "hemiazygous arch" (Figure 6). Lymph nodes do not have branches. Hence, this finding is also compatible with the vascular nature of the "nodule".

Based on the above mentioned anatomic characteristics the diagnosis of PLSVC was established. The lack of intravenous contrast was a great disadvantage and resulted in the initial false staging.

A lobectomy (LUL) was performed. Histological examination of sampled lymph nodes during surgery was negative for malignancy. Our patient is free of disease at follow-up after two years.

\section{Discussion}

Physicians should bear in mind that every node in the mediastinum is not a lymph node. The interpretation of CT scans should be made with extreme caution especially

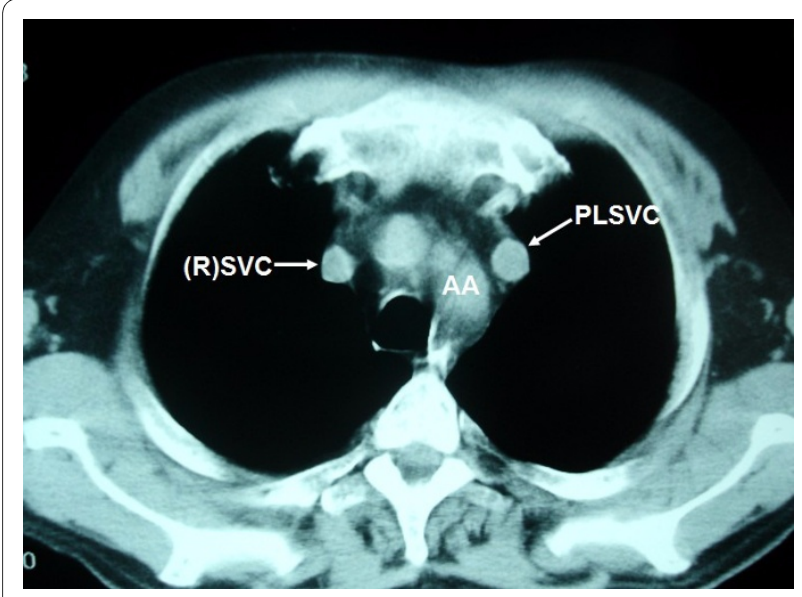

Figure 2 PLSVC is seen as a nodule with anatomic correlation to the left branchiocephalic vein

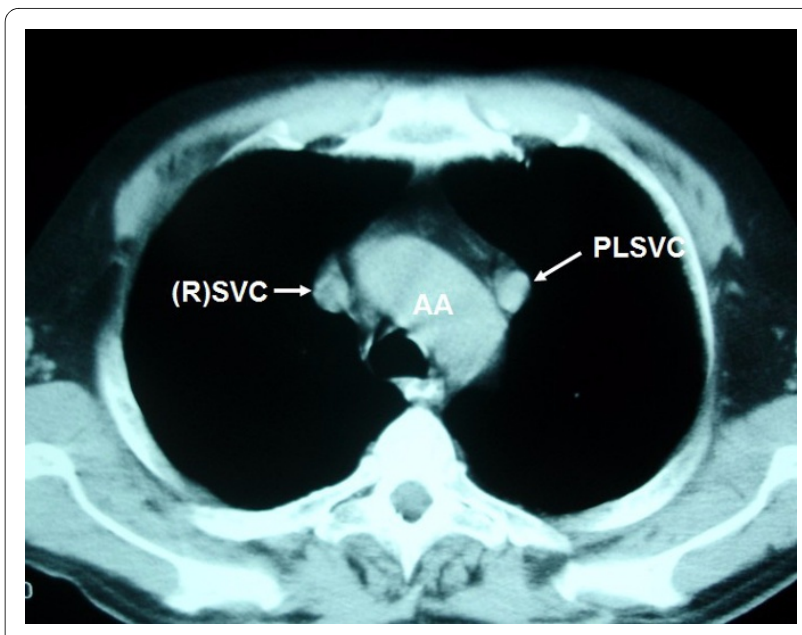

Figure 3 PLSVC is seen as a nodular opacity lateral to the aortic arch in continuous levels.

if intravenous contrast is not used. Each node should be examined in continuous levels. An elongated shape favors the possibility of a vascular structure. Possible anatomic relation to vessels should be sought as it will establish the diagnosis. The use of intravenous contrast is of utmost importance regarding mediastinal staging.

Nevertheless, sometimes intravenous contrast is not administrated (e.g. renal failure, allergies or even negligence). In such cases thorough knowledge of mediastinal anatomy (including normal variations) is essential in order to avoid mistakes.

\section{Conclusions}

We presented a case of a 57-year-old man with an operable (as was proved surgically) NSCLC of the LUL. This case demonstrates the difficulties in mediastinal staging especially when intravenous contrast is not used. The patient had a congenital vascular abnormality. Diagnos-

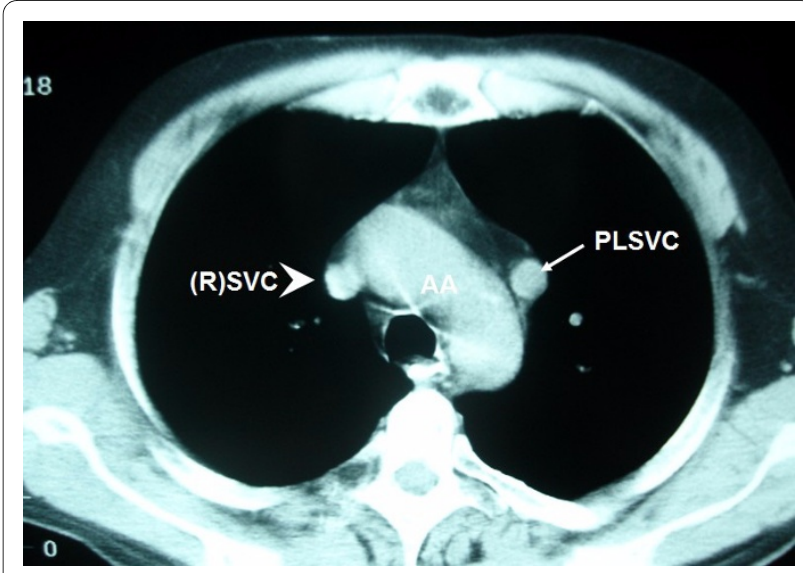

Figure 4 In patients with PLSVC the "normal" (R)SVC (arrowhead) is present in 80 to $90 \%$ 


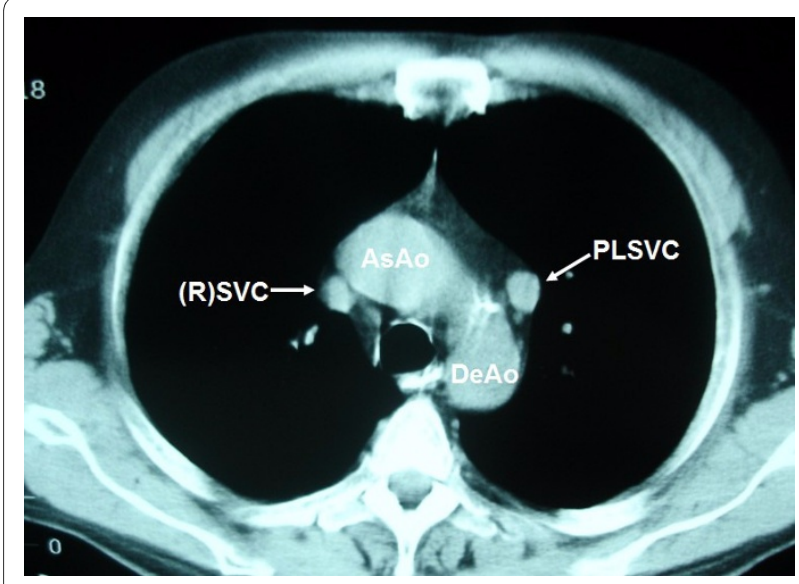

Figure 5 Note the relatively small size of the (R)SVC.

ing the left superior vena cava as a lymph node (lymph node station 6-para-aortic) would result in a false staging (IIIA, presence of $\mathrm{N}_{2}$ lymph node). The recognition of this vascular malformation changed dramatically the stage of the disease and therefore the therapeutic decisions and outcome of our patient.

\section{Consent}

Written informed consent was obtained from the patient for publication of this case report and any accompanying images. A copy of the written consent is available for review by the Editor-in-Chief of this journal.

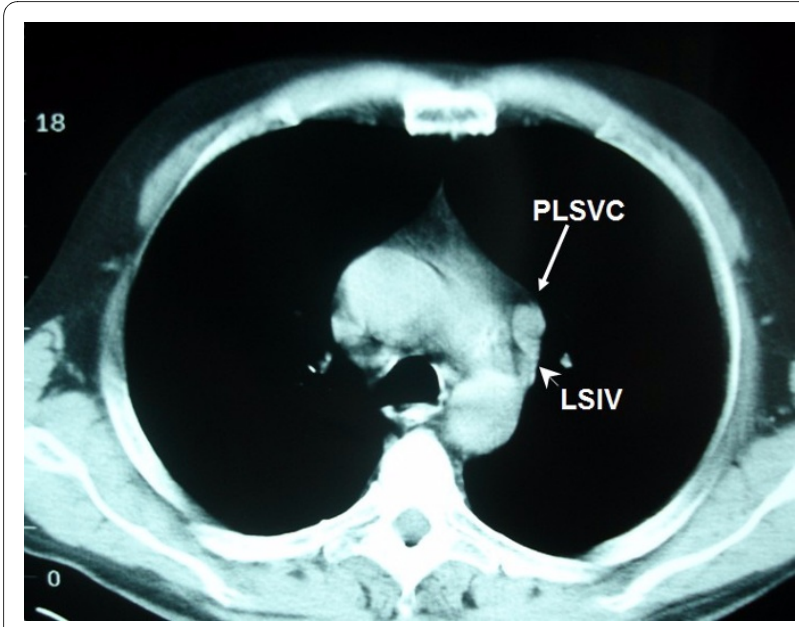

Figure 6 LSIV is seen (arrowhead) emptying into the PLSVC (arrow) (hemiazygous arch). * AA: aortic arch; AsAo: ascending aorta; DeAo: descending aorta; LP: left pulmonary artery; LSIV: left superior intercostal vein; MPA: main pulmonary artery; NSCLC: non small cell cancer; PLSVC: persistent left superior vena cava; RP: right pulmonary artery; (R)SVC: (right) superior vena cava.

\section{Abbreviations}

CT: computed tomography; LSIV: left superior intercostal vein; NSCLC: non small cell cancer; PLSVC: persistent left superior vena cava.

\section{Competing interests}

The authors declare that they have no competing interests.

\section{Authors' contributions}

Each author participated equally in the diagnosis. All authors read and approved the final manuscript.

\section{Author Details}

4th Respiratory Medicine Department, Athens Chest Disease Hospital Sotiria, Greece

Received: 15 December 2008 Accepted: 9 June 2010

Published: 9 June 2010

\section{References}

1. Buirski G, Jordan SC, Joffe HS, Wilde P: Superior vena caval abnormalities: Their occurrence rate, associated cardiac abnormalities and angiographic classification in a paediatric population with congenital heart disease. Clin Radiol 1986, 37:131-138.

2. Biffi M, Boriani G, Frabetti L, Bronzetti G, Branzi A: Left superior vena cava persistence in patients undergoing pacemaker or cardioverterdefibrillator implantation: a 10-year experience. Chest 2001 120:139-144

3. Lucas RV Jr, Krabill KA, et al: Abnormal systemic venous connections. In Moss and Adams Heart Disease in Infants, Children, and Adolescents: Including the Fetus and Young Adult 5th edition. Edited by: Emmanouilides GC, Riemenschneider TA, Allen HD et al. Baltimore, Williams \& Wilkins; 1995:874-878

4. Pahwa R, Kumar A: Persistent left superior vena cava: an intensivist's experience and review of the literature. South Med J 2003, 96(5):528-529.

5. Naidich DP, Muller NL, Krinsky GA, Webb WR, Vlahos I: Computed Tomography and Magnetic Resonance of the Thorax 4th edition. Lippincott Williams \& Wilkins; 2007:196-199.

doi: 10.1186/1752-1947-4-174

Cite this article as: Tzilas et al., Persistent left superior vena cava mistaken for nodal metastasis: a case report Journal of Medical Case Reports 2010, 4:174

\section{Submit your next manuscript to BioMed Central} and take full advantage of:

- Convenient online submission

- Thorough peer review

- No space constraints or color figure charges

- Immediate publication on acceptance

- Inclusion in PubMed, CAS, Scopus and Google Scholar

- Research which is freely available for redistribution

Submit your manuscript at www.biomedcentral.com/submit
C) Biomed Central 